\title{
Advantages and challenges of high-dose thermoluminescent detectors
}

\author{
V. Kortov*, Yu. Ustyantsev \\ Physical E' Engineering Institute, Ural Federal University, 19 Mira Str., 620002 Ekaterinburg, Russia
}

\section{H I G H L I G H T S}

- The examples of the materials for the high-dose luminescent detectors have been made.

- TL change in TLD-500 detectors after high dose $\gamma$-radiation has been shown.

- Using TL deep traps it is possible to measure the absorbed dose up to $100 \mathrm{kGy}$.

- Heating $\left(900^{\circ} \mathrm{C}, 1 \mathrm{~h}\right)$ of highly irradiated TLD-500 detectors restore their initial properties.

\section{A R T I C L E I N F O}

\section{Article history:}

Received 8 October 2012

Received in revised form

13 March 2013

Accepted 19 March 2013

\section{Keywords:}

Thermoluminescent detectors

High-dose measurements

Deep traps

High-temperature TL peaks

Restoration of luminescent detector

properties

\begin{abstract}
A B S T R A C T
The current status of high-dose luminescent detector investigations is discussed. The examples of successful applications of various materials for medium and high-dose luminescent detector creation are presented. High-dose irradiation effect on luminescence of TLD-500 $\left(\alpha-\mathrm{Al}_{2} \mathrm{O}_{3}: \mathrm{C}\right)$ detectors has been described. The challenges of detector properties restoration after high-dose irradiation are considered.
\end{abstract}

(c) 2013 Elsevier Ltd. All rights reserved.

\section{Introduction}

At present there is an intensive development of radiation technologies employing high-dose irradiation to modify material properties, sterilize medical products and to perform other industrial processes. High-dose detectors are also used in radiation monitoring of nuclear power station equipment and storages for spent nuclear fuel. In most cases measurement of radiation doses as high as several dozens or hundreds of kilograys is required. The well-known non-luminescent physical methods namely electron spin resonance (ESR), optical absorption (OA), calorimetry and chemical reactions in irradiated solutions are used for high-dose measurements. Such detectors have rather narrow useful dose range and not high measurement accuracy. At the same time significant progress in thermoluminescent detector (TLD) design for environmental and individual monitoring of ionizing radiation has

\footnotetext{
* Corresponding author. Tel.: +7 34337544 43; fax: +7 3433754415 .

E-mail address: vskortov@mail.ru (V. Kortov).
}

been made. Commercial detectors of various types have a wide dose useful range $(0.1 \mu \mathrm{Gy}-10 \mathrm{~Gy})$, high accuracy of dose measurement of different radiation types, low fading, dose measurements automatic possibility, opportunity of multiple uses of detectors. Unfortunately, the changes of their luminescent and dosimetric properties under high-dose irradiation have not been studied completely. Thus, high-dose luminescent detector development is an urgent issue today.

This paper offers brief analysis of the published data and results of our investigations into the thermoluminescence (TL) and dosimetric properties of some high-dose luminescent detectors.

\section{High-dose luminescent detectors existing nowadays}

To begin with, one can enumerate the materials for medium and high-dose luminescent detectors: single crystals of radiation resistant materials; amorphous materials (ceramic, glass); natural silicates (quartz, onyx); single crystals with deep traps including those created under high-dose irradiation; nanocrystalline compounds with various compositions. 
Table 1

Some examples of medium and high-dose measurements by means of luminescent detectors.

\begin{tabular}{|c|c|c|c|}
\hline $\begin{array}{l}\text { Chemical composition of } \\
\text { luminescent detectors }\end{array}$ & Type of irradiation & Dose (fluence) range & References \\
\hline $\begin{array}{l}\text { Composite ceramic, } \mathrm{BeO}-\mathrm{TiO}_{2} \\
\mathrm{Brazilian} \text { natural topaz, } \mathrm{Al}_{2}\left(\mathrm{SiO}_{4}\right)(\mathrm{F}, \mathrm{OH}) \\
\mathrm{YAlO}_{3}: \mathrm{Mn}^{2+} \text {, single crystals } \\
\mathrm{LiF}: \mathrm{Mg}, \mathrm{Cu}, \mathrm{P} \text {, polycrystalline detectors } \\
\mathrm{LiF}: \mathrm{Mg}, \mathrm{Cu}, \mathrm{P} \text {, nanocrystalline powder } \\
\mathrm{ZnS}: \mathrm{Cu} \text {, nanocrystalline powder } \\
\alpha-\mathrm{Al}_{2} \mathrm{O}_{3}: \mathrm{C}, \mathrm{Mg} \text {, nanocrystalline ceramic } \\
\mathrm{K}_{2} \mathrm{Ca}_{2}\left(\mathrm{SO}_{4}\right)_{3}: \mathrm{Eu} \text {, nanocrystalline powder }\end{array}$ & $\begin{array}{l}\gamma(\mathrm{Co}-60) \\
\gamma(\mathrm{Co}-60) \beta(\mathrm{Sr}-90) \\
\gamma(\mathrm{Co}-60) \\
\gamma(\mathrm{Co}-60) \\
\gamma(\mathrm{Cs}-137) \\
\beta(\mathrm{Sr}-90) \\
\gamma(\mathrm{Co}-60) \\
48 \mathrm{MeV} \mathrm{U}^{3+} \\
75 \mathrm{MeV} \mathrm{C}^{6+} \\
90 \mathrm{MeV} \mathrm{O}^{7+}\end{array}$ & $\begin{array}{l}0.01 \div 10^{3}, \mathrm{~Gy} \\
10^{-2} \div 10^{3}, \mathrm{~Gy} \\
10 \div 10^{3}, \mathrm{~Gy} \\
1 \mu \mathrm{Gy}-10^{3} \mathrm{kGy} \\
10^{-1} \div 10^{4}, \mathrm{~Gy} \\
1 \div 2.5 \cdot 10^{3}, \mathrm{~Gy} \\
10 \div 10^{4}, \mathrm{~Gy} \\
\text { Up to } 10^{12}, \\
\text { ions } / \mathrm{cm}^{2}\end{array}$ & $\begin{array}{l}\text { Kortov et al., } 1995 \\
\text { Souza et al., } 2002 \\
\text { Zhydachevskii et al., } 2010 \\
\text { Obryk et al., 2011a } \\
\text { Salah et al., } 2007 \\
\text { Yazici et al., } 2007 \\
\text { Kortov and Ustyantsev, } 2011 \\
\text { Salah, } 2011\end{array}$ \\
\hline
\end{tabular}

A number of successful applications of high-dose luminescent detectors have been described. Table 1 presents some examples of various luminescent materials which can be used for high-dose detector creation. It is seen that the maximal registered dose of these detectors varies from $1 \mathrm{kGy}$ to $1000 \mathrm{kGy}$. Among the existing high-dose luminescent detectors the polycrystalline LiF: $\mathrm{Mg}, \mathrm{Cu}, \mathrm{P}$ detectors have the best dosimetric parameters. For the first time behavior of these detectors under high-dose gamma-irradiation was studied by Polish researchers (Bilski et al., 2008; Obryk et al., 2009). It was found that the main dosimetric peak at $200{ }^{\circ} \mathrm{C} \mathrm{di-}$ minishes for doses starting from about $50 \mathrm{kGy}$ under Co-60 $\gamma$-rays irradiation. With the further growth of the dose a new TL peak formed at $450^{\circ} \mathrm{C}$ and grew with the increase of the dose (Bilski et al., 2010). The dose response of this peak was linear in the range from $50 \mathrm{kGy}$ to $500 \mathrm{kGy}$. Brown coloring of TLDs and TL emission spectrum change (Mandowska et al., 2010) can serve as an evidence of the formation of radiation defects at high-dose irradiation in the detector under study. Such defects give rise to new recombination centers responsible for the appearance of high temperature $\mathrm{TL}$ peak sensitive to high dose irradiation. It was shown also that LiF:Mg,Cu,P detectors can be used for high-dose measurement of other types of radiation namely electron (Bilski et al., 2010), proton (Obryk et al., 2010), thermal neutron (Obryk et al., 2011b), alpha-particles (Olko et al., 2011).

\section{High-dose irradiation effect on luminescent and dosimetric properties of TLD-500 detectors}

The luminescent and dosimetric properties of well-known highly sensitive TLD-500 detectors based on anion-defective alumina $\left(\alpha-\mathrm{Al}_{2} \mathrm{O}_{3}: \mathrm{C}\right)$ single crystals after high-dose irradiation were studied in our experiments. Two types of irradiation sources were used in our investigations: industrial $\left({ }^{60} \mathrm{Co}\right)$ device Gammatok - 100 with exposure dose rate $1.3 \mathrm{kGy} / \mathrm{h}$ and pulse electron accelerator KLAVI which has the following parameters: pulse length is $2 \mathrm{~ns}$, the middle electron energy is $180 \mathrm{keV}$, current density is $60 \mathrm{~A} / \mathrm{cm}^{2}$. The medium absorbed dose (in water) at one pulse is $1.5 \mathrm{kGy}$. TL was registered at the heating up to $873 \mathrm{~K}$ with the rate of $2 \mathrm{~K} / \mathrm{sec}$. The PEM with the maximum sensitivity in the range $410-430 \mathrm{~nm}$ was used.

Fig. 1 shows the changes of TL glow curves in the temperature range of the main dosimetric peak. It is seen that with low doses ( $8 \mathrm{mGy}$ ) the known dosimetric TL peak is registered at $453 \mathrm{~K}$. When detectors are irradiated with the dose up to $10 \mathrm{kGy}$, TL peak shape does not change. Its expected shift to the range of low temperatures is observed. With that TL peak connected with the first deep trap starts forming at $573 \mathrm{~K}$.

When the dose is over $10 \mathrm{kGy}$ alongside with the main dosimetric TL peak a new TL peak begins to form at $393 \mathrm{~K}$ (Fig. 2). This peak grows as the dose increases. With the dose about $100 \mathrm{kGy}$, a new TL peak intensity exceeds that of the main dosimetric maximum registered at $T \approx 423 \mathrm{~K}$. It can be assumed that under high dose irradiation the new stable shallow traps responsible for TL peak at $393 \mathrm{~K}$ form. The intensity of this peak grows as the dose increases.

Dose response of the main dosimetric peak $\left(T_{\mathrm{m}}=453-423 \mathrm{~K}\right)$ was first measured by us in the wide dose range from $10 \mathrm{mGy}$ to $100 \mathrm{kGy}$. As it could be expected, the linear dependence of TL intensity on the dose was limited by the dose of $10 \mathrm{~Gy}$. Then, a saturation and slight drop of TL intensity followed. However, in the dose range from $10 \mathrm{~Gy}$ to $100 \mathrm{kGy}$ TL intensity remained on a medium level close to the maximum one. This meant that the centers responsible for the main dosimetric peak were not destroyed under high-dose irradiation. This result proves high radiation resistance of TL centers in $\alpha-\mathrm{Al}_{2} \mathrm{O}_{3}$ :C. However, the main dosimetric peak cannot be used for high-dose measurements.

Crystals with deep traps are very prospective for high-dose measurements, because efficient filling of the deep traps starts with high-dose irradiation. When the dose is high the traps of main dosimetric peak are empty and do not compete with deep traps in charge carrier trapping. Deep traps exist in non- irradiated $\alpha-\mathrm{Al}_{2} \mathrm{O}_{3}: \mathrm{C}$ crystals and are found after intensive irradiation under hightemperature heating (Milman et al., 1998; Nikiforov et al., 2011).

We studied the TL of deep traps in $\alpha-\mathrm{Al}_{2} \mathrm{O}_{3}: \mathrm{C}$ single crystals after nanosecond pulse electron irradiation. Fig. 3 presents the typical high-temperature TL glow curve with peaks from deep traps. It is seen that after high irradiation dose $(30 \mathrm{kGy})$ several TL peaks from deep traps are observed. TL peaks are broadened compared to the similar peaks of $\alpha-\mathrm{Al}_{2} \mathrm{O}_{3}: \mathrm{C}$ single crystals before irradiation

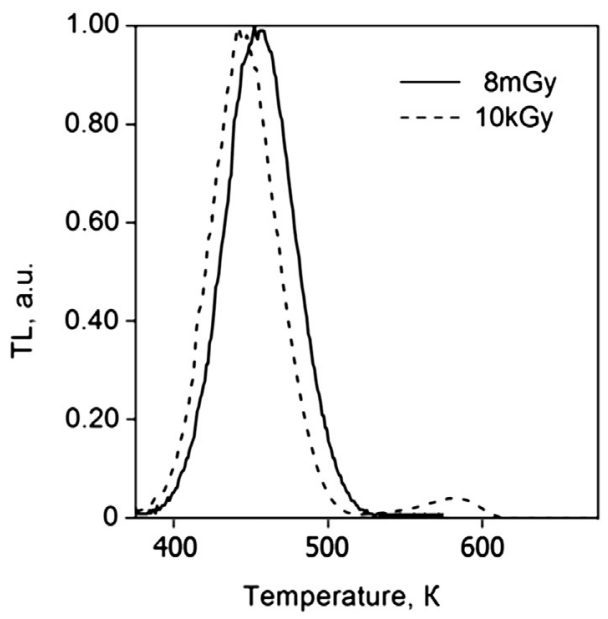

Fig. 1. Normalized TL glow curves of TLD-500 detectors after low and high dose irradiation $\left({ }^{60} \mathrm{Co}\right)$ 


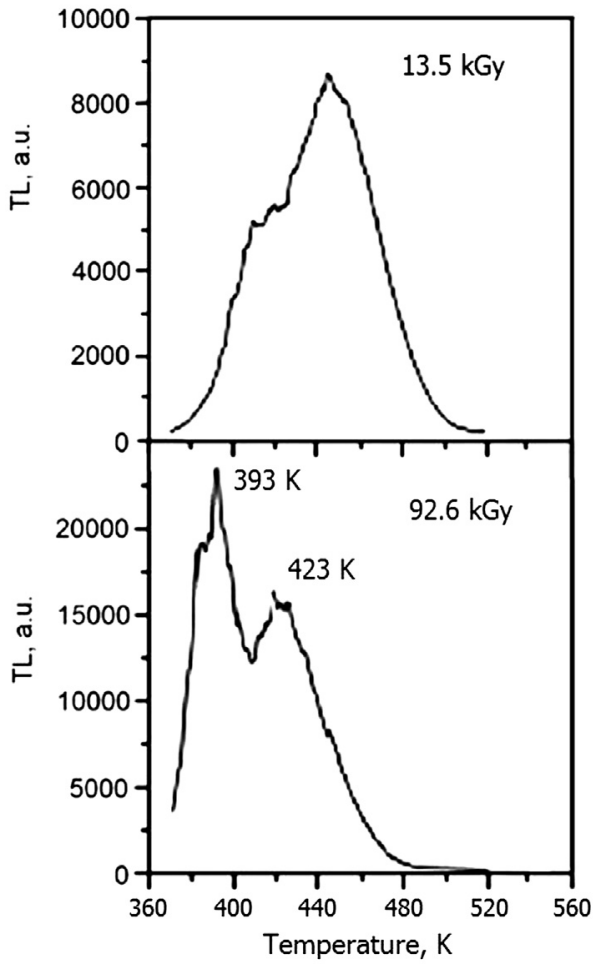

Fig. 2. TL glow curves of TLD-500 detectors with various high-doses of ${ }^{60} \mathrm{Co} \gamma$-rays.

(Milman et al., 1998). Deconvolution allows singling out several elementary TL peaks. Dose response was measured for the high peak at $700 \mathrm{~K}$. It was found that TL peak height changes linearly in the range from $1.5 \mathrm{kGy}$ to $100 \mathrm{kGy}$.

It has been shown that some deep traps in $\alpha-\mathrm{Al}_{2} \mathrm{O}_{3}: \mathrm{C}$ are emptied in the range of $600-900{ }^{\circ} \mathrm{C}$ (Akselrod and Gorelova, 1993; Soni et al., 2012). However, it is difficult to experimentally register TL peaks at such high temperatures. The problem can be solved though by means of recently developed thermally assisted OSL (TAOSL) method (Polymeris et al., 2010; Mishra et al., 2011; Soni et al., 2012). According to this method a high-dose irradiated sample is exposed to intensive light from blue or dark-blue LED. This leads to carrier phototransfer from deep traps to shallow ones. While heated TL peaks form at lower temperature (up to $300{ }^{\circ} \mathrm{C}$ ). Experimentally-obtained TA-OSL curves of $\alpha-\mathrm{Al}_{2} \mathrm{O}_{3}: \mathrm{C}$ detectors after high-dose irradiation are given in Soni et al. (2012). These curves contain 2 peaks at $121{ }^{\circ} \mathrm{C}$ and $232{ }^{\circ} \mathrm{C}$ which are easy to register. With that, integrated TA-OSL dose response from deep traps in $\alpha$ $\mathrm{Al}_{2} \mathrm{O}_{3}: \mathrm{C}$ changes in the range of 6 orders and the maximum registered dose corresponds to linear dose response not less than 10 kGy. Our results (Fig. 3) and published data (Soni et al., 2012) show that TLD-500 detectors can be well used for high-dose measurements in deep trap TL registration. TA-OSL method allows one to apply the heating systems of the commercial readers for high-dose measurements.

The issue of the restoration of the detector initial TL properties after high-dose irradiation is of particular importance. In our special experiments TLD-500 detectors were irradiated with the doses 80-100 kGy and were heated up to $600{ }^{\circ} \mathrm{C}$ to measure TL from deep traps. After cooling of the detector the TL measurement was repeated immediately but TL was absent. Then the detector was stored in dark at room temperature without irradiation. Under reheating $24 \mathrm{~h}$ later the residual radiation background up to $10 \mathrm{mGy}$ was registered in the main dosimetric peak. This slow process of charge carrier transfer to the traps of the main
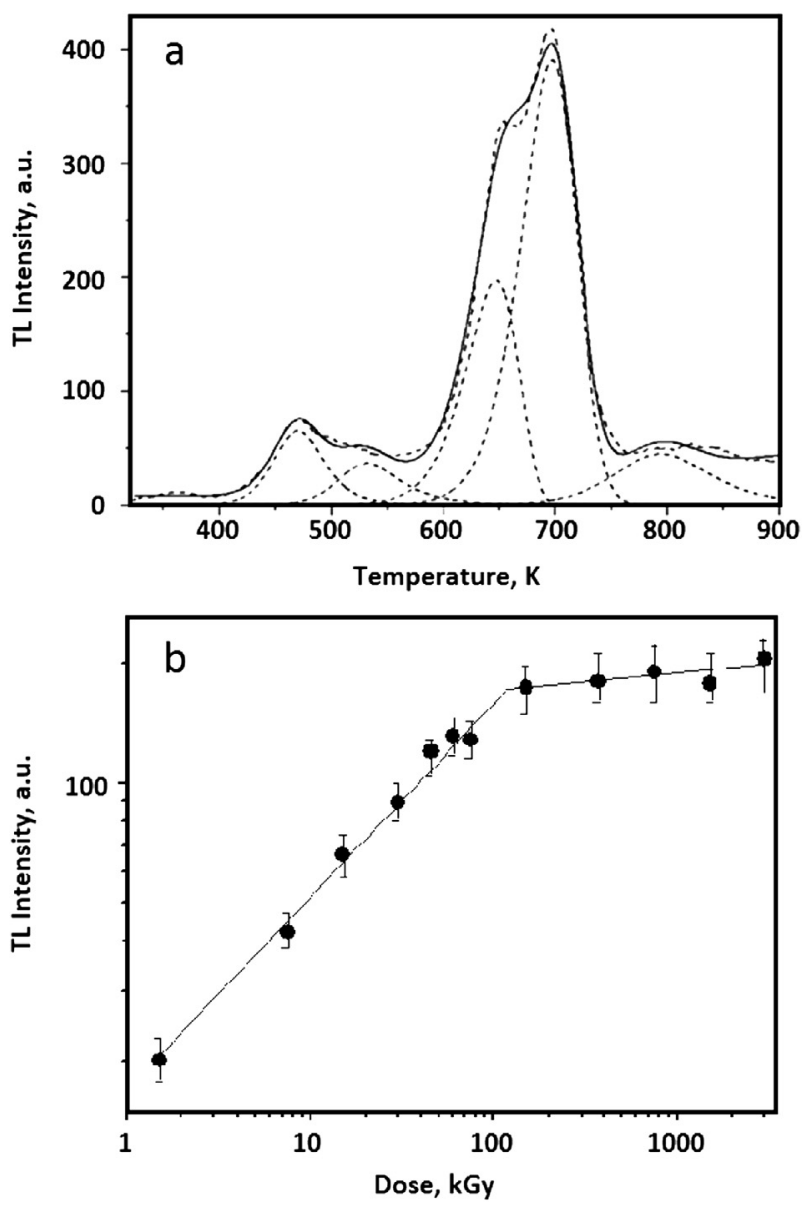

Fig. 3. Typical TL glow curve from deep traps (a) and dose response (b) of TL peak at $T=700 \mathrm{~K}$ of TLD-500 detectors irradiated by nanosecond pulse electron beam with dose $30 \mathrm{kGy}$. Solid line is the experimental curve, dashed lines correspond to the deconvolution results.

dosimetric peak after high-dose irradiation requires supplementary studies. Another consequence of the high-dose irradiation was observed in our experiments. The sensitivity of detectors increases by 2 or 3 times. It is found experimentally that annealing of TLD500 detectors in air at $T=900{ }^{\circ} \mathrm{C}$ during $1 \mathrm{~h}$ allows one to except background and to restore the initial sensitivity of the detectors. One can suppose that it is the temperature at which deep traps in $\alpha$ $\mathrm{Al}_{2} \mathrm{O}_{3}: \mathrm{C}$ are emptied fully and initial concentration of luminescent centers and their charge are restored. After annealing at the given temperature TLD-500 detectors earlier irradiated with a high dose can be used to measure repeatedly both low and high doses.

\section{Conclusions}

1. At present several successful researches on luminescent and dosimetric properties of some materials suitable for high-dose detector manufacture have been carried out. A number of such materials can be expected to increase, as there is no tissue equivalence requirement for high-dose luminescent detectors.

2. Highly sensitive luminescent detectors (e.g. LiF:Mg,Cu,P, $\alpha$ $\mathrm{Al}_{2} \mathrm{O}_{3}: \mathrm{C}$ ) can be used to measure both low doses in personal radiation monitoring and high doses in industrial dosimetry. Moreover, all advantages of the luminescent dosimetry method are exploited compared to OA, ESR and calorimetry methods.

3. High-dose luminescent dosimetry is high-temperature one in the majority of cases. It employs TL peaks from deep traps 
present in the detector material or brought about by high-dose irradiation.

4. TA-OSL method is an excellent advancement of high-dose luminescent dosimetry with involvement of deep traps.

\section{References}

Akselrod, M.S., Gorelova, E.A., 1993. Deep traps in highly sensitive $\alpha-\mathrm{Al}_{2} \mathrm{O}_{3}$ :C TLD crystals. Nucl. Tracks Radiat. Meas. 21, 143-146.

Bilski, P., Obryk, B., Olko, P., Mandowska, E., Mandowski, A., Kim, J., 2008. Characteristics of LiF: $\mathrm{Mg}, \mathrm{Cu}, \mathrm{P}$ thermoluminescence at ultra-high dose range. Radiat. Meas. 43, 315-318.

Bilski, P., Obryk, B., Stuglik, Z., 2010. Behaviour of LiF: Mg, Cu, P and LiF: Mg, Ti thermoluminescent detectors for electron doses up to $1 \mathrm{MGy}$. Radiat. Meas. 45, 576-578.

Kortov, V.S., Milman, I.I., Lesz, J., 1995. Exoelectron emission and luminescence of conductive BeO ceramics. Sci. Rep. Techn. Univ. Opole 15 (N209), 31-40.

Kortov, V., Ustyantsev, Yu., 2011. Chernobyl accident and high dose measurements. In: Proc. 7th Internat. Workshop on Ioniz. Radiat. Monitoring, December 3-4, Oarai, Japan, pp. 281-294.

Mandowska, E., Bilski, P., Obryk, B., Mandowski, A., Olko, P., Kim, J., 2010. Spectrally resolved thermoluminescence of highly irradiated $\mathrm{LiF}: \mathrm{Mg}, \mathrm{Cu}, \mathrm{P}$ detectors. Radiat. Meas. 45, 579-582.

Milman, I.I., Kortov, V.S., Nikiforov, S.V., 1998. An interactive process in the mechanism of the thermally stimulated luminescence of anion-defective $\alpha-\mathrm{Al}_{2} \mathrm{O}_{3}$ crystals. Radiat. Meas. 29 (N 3-4), 401-410.

Mishra, D.R., Rawat, N.S., Kulkarni, M.S., Bhatt, B.C., Sharma, D.N., 2011. Method of measuring thermal assistance energy associated with OSL traps in $\alpha-\mathrm{Al}_{2} \mathrm{O}_{3}$ :C phosphor. Radiat. Meas. 46, 635-642.

Nikiforov, S.V., Kortov, V.S., Nosal, A.A., Moiseikin, E.V., 2011. On the role of trapping centers in the interactive mechanism of the trap interaction in anion-defective alumina single crystals. Phys. Solid State 53 (N 10), 2141-2145.
Obryk, B., Bilski, P., Budzanowski, M., Fuerstner, M., Glaser, M., Ilgner, C., Olko, P. Pajor, A., Stuglik, Z., 2009. Development of a method for passive measurement of radiation doses at ultra-high dose range. IEEE Trans. Nucl. Sci. 56, 37593763.

Obryk, B., Bilski, P., Glaser, M., Fuerstner, M., Budzanowski, M., Olko, P., Pajor, A. 2010. The response TL lithium fluoride detectors to $24 \mathrm{GeV} / \mathrm{c}$ protons for doses ranging up to 1 MGy. Radiat. Meas. 45, 643-645.

Obryk, B., Bilski, P., Olko, P., 2011a. Method of thermoluminescent measurements of radiation doses from micrograys up to megagray with a single $\mathrm{LiF}: \mathrm{Mg}, \mathrm{Cu}, \mathrm{P}$ detector. Radiat. Prot. Dosim. 144, 543-547.

Obryk, B., Glaser, M., Mandic, I., Bilski, P., Sas-Bieniarz, A., 2011b. Response of varicose types of lithium fluoride MCP detectors to high and ultra-high thermal neutron doses. Radiat. Meas. 46, 1882-1885.

Olko, P., Bilski, P., Gieszczyk, L., Grzanka, L., Obryk, B., 2011. Microdosimetric analysis of response of LiF: Mg, Cu, P (MCP-N) TL detectors for alpha-particles and ultrahigh doses of gamma-rays. Radiat. Meas. 46, 1349-1352.

Polymeris, G.S., Raptis, S., Afouxenidis, D., Tsirbiganis, N.C., Kitis, G., 2010. Thermally assisted OSL from deep traps in $\mathrm{Al}_{2} \mathrm{O}_{3}$ :C. Radiat. Meas. 45, 519-522.

Salah, N., Sahare, P.D., Rupasov, A.A., 2007. Thermoluminescence of nanocrystalline LiF: $\mathrm{Mg}, \mathrm{Cu}$. P. J. Lumines. 124, 357-364.

Salah, N., 2011. Nanocrystalline materials for the dosimetry of heavy charged particles: a review. Radiat. Phys. Chem. 80,1-10.

Soni, A., Mishra, D.R., Bhatt, B.C., Gupta, S.K., Rawat, N.S., Kulkarni, M.S. Sharma, D.N., 2012. Characterization of deep energy level defects in $\alpha-\mathrm{Al}_{2} \mathrm{O}_{3}: \mathrm{C}$ using thermally assisted OSL. Radiat. Meas. 47, 111-120.

Souza, D.N., Lima, J.F., Valerio, M.E.G., Caldas, V.E., 2002. Performance of pellets and composites of natural colorless topaz as radiation dosimeters. Radiat. Prot Dosim. 100 (1-4), 413-416.

Yazici, N., Öztag, M., Bedir, M., 2007. The thermoluminescence properties of copper doped ZnS nanophosphors. Opt. Mater. 29, 1091-1096.

Zhydachevskii, Ya., Suchocki, A., Berkowski, M., Bilski, P., Warchol, S., 2010. Characterization of $\mathrm{YAl}_{2} \mathrm{O}_{3}: \mathrm{Mn}^{2+}$ thermoluminescent detectors. Radiat. Meas. 45, 516-518. 